\title{
Descrição Preliminar da Fonologia do Oro Waram Xijein (Família Txapakúra)
}

\author{
Preliminary Description of the Phonology of \\ Oro Waram Xijein (Txapakúra Family)
}

\author{
Fábio Pereira Couto ${ }^{1}$ \\ https://orcid.org/0000-0003-0712-6928
}

Marcelina Oro Waram Xijein ${ }^{2}$

https://orcid.org/0000-0002-8075-9038

DOI: $10.26512 /$ rbla.v12i1.35325

Recebido em outubro/2020 e aceito em novembro/2020

Resumo

A presente pesquisa objetivou a análise e descrição fonológica, de forma preliminar, do Oro Waram Xijein, língua pertencente ao subramo Wari da família Txapakúra. O povo Oro Waram Xijein vive no oeste do estado de Rondônia, no município de Guajará Mirim, na fronteira com a Bolívia. A pesquisa em tela é fruto de estudos desenvolvido no segundo semestre de 2019 e primeiro de 2020, com a fundamental colaboração de três falantes nativos da variante Oro Waram Xijein, sendo um deles coautor do presente trabalho, em um projeto maior no âmbito do Laboratório de Língua e Culturas Indígenas da Universidade Federal de Rondônia. O repertório teórico e metodológico que subsidiaram esta pesquisa está ancorando, principalmente, na linguística descritiva em trabalhos como Pike (1943, 1947), Jakobson (1939), Ladefoged e Maddieson (1996), Ladefoged (1975), Couto (2016), Apontes (2015) e Rodrigues (2002). Como resultados desse estudo, descrevemos para Oro Waram Xijein treze segmentos consonantais e cinco vocálicos, sendo um deles, o $/ \mathrm{tg}_{\mathrm{B}} /$, extremamente raro nas línguas do mundo. Descrevemos ainda o molde silábico (C)V(C) para a variante em estudo, sedo a forma CV o padrão prototípico na língua Oro Waram Xijein. O acento primário é fruto de realização fonética. Descrevemos também alguns

1 Professor Dr. Adjunto, do Curso de Licenciatura Intercultural da Universidade Federal de Rondônia (UNIR), campus de Ji-Paraná. Coordenador do Laboratório de Línguas e Cultura Indígena da UNIR. Coordenador do programa Saberes Indígenas da rede UNIR-UFAC. Pesquisador do Laboratório de Línguas e Literatura Indígenas da Universidade de Brasília (UnB).

2 Graduanda do Curso de Licenciatura em Educação Intercultural da Universidade Federal de Rondônia (UNIR), campus de Ji-Paraná. Professora indígena da Secretária de Educação de Rondônia (SEDUC). 
processos fonológicos existentes neste dialeto, como nasalização, alongamento e redução vocálica, pré-nasalização, laringalização, aspiração, oralização entre outros.

Palavras-chave: Oro Waram Xijein, Família Txapakúra, Fonologia.

\begin{abstract}
This research aimed at the preliminary analysis and phonological description of the Oro Waram Xijein, a language belonging to the Wari sub-family of the Txapakúra family. The Oro Waram Xijein people live in the northwest of the state of Rondônia, in the municipality of Guajará Mirim, on the border with Bolivia. The research on screen is the result of studies developed in the second semester of 2019 and the first of 2020, with the fundamental collaboration of three native speakers of the Oro Waram Xijein variant, one of whom is co-author of this work, in a larger project within the Laboratory Indigenous Language and Cultures of the Federal University of Rondônia. The theoretical and methodological repertoire that supported this research is anchoring, mainly, in the descriptive linguistics in works such as Pike (1943, 1947), Jakobson (1939), Ladefoged and Maddieson (1996), Ladefoged (1975), Couto (2016), Apontes (2015) and Rodrigues (2002). As result of this study, we describe for Oro Waram Xijein thirteen consonant and five vowel segments, one of which, the $/ \mathrm{ta}_{\mathrm{B}} /$, is extremely rare in the languages of the world. We also describe the syllabic mold $(\mathrm{C}) \mathrm{V}(\mathrm{C})$ for the variant under study, with the $\mathrm{CV}$ form being the prototypical pattern in the Oro Waram Xijein language. The primary accent is the result of phonetic realization. We also describe some phonological processes existing in this dialect, such as nasalization, elongation and vowel reduction, pre-nasalization, laryngealization, aspiration, oralization and others.
\end{abstract}

Keywords: Oro Waram Xijein, Txapakúra Family, Phonology.

Enquanto a fonética procura coletar as informações mais exaustivas sobre a matéria sonora bruta, em suas propriedades fisiológicas e físicas, a fonêmica e fonologia, em geral, intervém para aplicar estritamente critérios linguísticos. (Jakobson e Halle 1956, $7^{3}$ ).

\title{
Introdução
}

O presente trabalho tem como foco principal a descrição preliminar da fonologia da variante Oro Waram Xijein. A pesquisa foi desenvolvida no Laboratório de Línguas e Culturas Indígenas da Unir, como parte de atividades inerentes ao programa de pesquisa "Descrição, análise, documentação e ensino de línguas indígenas faladas em Rondônia", no âmbito do Curso de Licenciatura em Educação Intercultural da Universidade Federal de Rondônia do campus de Ji-Paraná.

3 Do original: While phonetics seeks to collect the most exhaustive information on gross sound matter, in its physiological and physical properties, phonemics, and phonology in general, intervenes to apply strictly linguistic criteria to the sorting and classification of the material registered by phonetics. 
Nesse sentido, o nosso propósito de fazer um estudo voltado às questões de compreensão e descrição da fonética e fonologia da língua diz respeito principalmente ao fato de uma indígena, falante nativa, ser coautora deste trabalho, além de ela ser professora da escola de sua comunidade, no caso, a Escola Indígena Estadual de Ensino Fundamental Paulo Saldanha Sobrinho, na aldeia Sagarana, onde ela vivencia, faz muito tempo, com problemas tanto de descrição de sua 'língua', como também da representação gráfica dos sons, como também no que se refere aos estudos linguísticos especificamente da variante Oro Waram Xijein. Ou seja, há uma carência enorme em estudos sobre essa variante, o que provoca discordância sobre questões linguísticas, inclusive no que se refere à ortografia e à produção de materiais didáticos, já que para isso é necessário ter estudos linguísticos substanciais e consolidação de uma escolha gráfica que realmente tenha bases sólidas linguísticas e pedagógicas.

No sentido de encontrar soluções para esses problemas é que propomos fazer essa pesquisa de caráter preliminar, sobre a ótica da linguística descritiva, para que esse estudo possa ajudar e motivar, futuramente, outros estudos e aprofundamentos sobre esse dialeto.

Para esta investigação, nosso trabalho tem com base teórica e metodológica a descrição e análise linguística da língua, procedendo para isso com formação de um corpus substanciado por meio de gravações e análise de mais de 1500 dados gerados com a fundamental participação de três colaboradores falantes nativos da língua Oro Waram Xijein e também com bom domínio da língua portuguesa, sendo duas mulheres, uma com idade de 27 e outra com idade de 29; já o colaborador masculino tem a idade de 42 anos. Todos esses colaboradores são professores de língua nativa e língua portuguesa em suas comunidades e também são graduandos do Curso de Licenciatura Intercultural da Unir de JiParaná.

A gravação para a formação do corpus se deu utilizando-se de um Gravador Digital estéreo ZOOM H4 da Sony, com taxa de registro configurado em 24bits-48khz em ambiente silencioso, configuração essa que é recomendada por especialistas como Barbosa e Madureira (2015) e Couto (2016), por exemplo. Após a gravação, foi feita a conversão dos arquivos para mono com a finalidade de observação acústica e transcrição fonética com o auxílio do programa PRAAT, sendo armazenada em documento word do programa Office da Windows somando cerca de 1500 itens lexicais entre palavras, frases e textos.

Para o suporte teórico e metodológico, foi importante trabalhos como o de Rodrigues (2002), Apontes (2015), Couto (2016), Barbosa e Madureira (2015), Everett e Kern (2006), Ladefoged (2001, 1975), Ladefoged e Maddieson (1996), Pike (1943), Ramirez (2010), Aikenvald e Dixon (1999a) entre outros. 


\section{O povo Oro Waram Xijien, subgrupo Wari, família Txapakúra: aspectos socioculturais e linguísticos}

Os Oro Waram Xijein, de forma geral na literatura linguística, são conhecidos como Wari ('nós', 'gente') que é a autodenominação que dá nome ao grupo que é composto por outros oito subgrupos ('dialetos'), que somam atualmente cerca de 2.429 pessoas (IBGE 20104). O povo, pertencente a esse subgrupo, vive em vários afluentes do rio Pacaas Novos e em outros rios como o próprio Mamoré, localizado no noroeste do estado brasileiro de Rondônia, em região de fronteira com a Bolívia. Muita gente também denomina esse povo pelo nome do rio Pacaas Novos (Rodrigues 2002).

Para o presente estudo, e conforme o povo se autodenomina, usaremos a terminologia Oro Waram Xijein para se referir especificamente ao dialeto e ao povo foco de nossa pesquisa, que pertence ao subgrupo denominado de Wari, que por sua vez pertence ao grupo maior, que dá nome à família linguística denominada de Txapakúra. Assim, quando for necessário se referir à família, usaremos o termo Txapakúra, como já utilizado na literatura pertinente, como, por exemplo, Rodrigues (2002). Sobre esse subgrupo (Wari), Everett afirma:

Esta autodenominação difere curiosamente dos nomes de subgrupos, como 'Oro Nao', o nome do subgrupo cujo dialeto estamos descrevendo aqui, por não ter a palavra coletiva 'oro'. No entanto, o povo Pacaas Novos rejeitou nossas tentativas de usar a frase 'Oro Wari' 'todas as pessoas' como a autodenominação de todo o grupo, insistindo que o termo correto era simplesmente 'Wari' (Everett e Kern 2006: prefácio) . $^{5}$ (Grifos do autor).

No livro intitulado 'Línguas Brasileiras: para o conhecimento das línguas indígenas', na sua edição atualizada de (2002), Rodrigues afirma, com dados de Curt Nimunedajú ${ }^{6}$, que:

No vale do Guaporé e nos afluentes da margem direita do rio Madeira, no oeste de Rondônia e no sul do Amazonas, estendia-se até há não muito uma das famílias linguísticas menos conhecidas, a família Txapakúra. A ela se

\footnotetext{
4 Informações conforme site do IBGE, disponível em: <http://www.funai.gov.br/arquivos/ conteudo/ascom/2013/img/12-Dez/pdf-brasil-ind.pdf> Acesso em: 05 de fev. de 2020.

5 Do original: This autodenomination differs interestingly from subgroup names, such as 'Oro Nao', the name of the subgroup whose dialect we are describing here, in that it lacks the collective word 'oro'. However, the Pacaas Novos people rejected our attempts to use the phrase 'Oro Wari' 'all the people' as the autodenomination of the entire group, insisting that the correct term was simply Wari' (Everett e Kern 2006: preface).

6 Dados do livro de Curt Nimunedajú, denominado "As tribos do alto Madeira" in Jounal de la Societé des Américanistes de Paris, tomo XVII, 1925:137-172, conforme citado por Rodrigues $(2002,76)$.
} 
filiam as línguas dos Pakaanóva e dos Urupá em Rondônia e a dos Torá no Amazonas, (também as do Moré na Bolívia). Já nos séculos passados os Torá eram os representantes mais setentrionais da família. Ainda não existe nenhum estudo científico das línguas da família Txapakúra, embora haja missionários (Missão Novas Tribos) que conhecem e têm analisado a língua dos Pakaanóva. (Rodrigues 2002:76).

Cada subgrupo possui um nome, que designa o povo e também o dialeto, que são: Oro Nao, Oro Eo, Oro At, Oro Mon, Oro Waram, ${ }^{7}$ Oro Waram Xijein, Oro Win e Oro Yowin. O morfema \{oro-\}, presente em todos os nomes desse subgrupo, é uma partícula que expressa a ideia de coletivo, podendo ser melhor entendida como 'povo', 'grupo'.

$\mathrm{Na}$ tabela 1 pode-se verificar, de forma comparativa, a relação de semelhança existente entre as línguas Torá, Urupá e Oro waram Xijein, todas línguas da família Txapakúra. A tabela original foi elaborada preliminarmente por Rodrigues $(2002,76)$.

\section{Tabela 1 - Dados de comparação lexical de línguas da família Txapakúra, sub-} grupo Wari, adaptada de Rodrigues (2002, 76).

\begin{tabular}{c|c|c|c} 
Palavras & Torá & Urupá & Oro Waran Xijein \\
\hline dente & iat & ieti & jat \\
\hline língua & kapiak & kapiaka & petehet \\
\hline olho & tok & tyke & tok \\
\hline mão & um & tipra & ym \\
\hline sol & apyto & kumen & Jina \\
\hline terra & timak & manakã & makan
\end{tabular}

Rodrigues $(2002,76)$, com adaptações ao inserirmos dados do Oro Waran Xiejin.

Os dados da tabela acima, mesmo que seja um pequeno recorte, evidenciam a similaridade lexical entre essas línguas, principalmente para as palavras dente e olho. Também há similaridade para a palavra terra, entre o Oro Waran Xijein e a língua Urupá.

7 Como já considerado por Apontes (2015), Everett e Kern (2006), Maeda (2000), Ramirez (2002) e Sousa (2009), entendemos, até o momento, mesmo que haja diferenças consideráveis estre estas variantes, que são dialetos e não línguas, mas sabemos que há a necessidade de realização de trabalhos que investigue e comparem essas variantes de forma mais detalhada e aprofundada para que se possa certificar de forma mais contundente se essas 'variantes' são realmente variantes ou se já se trata de línguas distintas como postulado por alguns professores indígenas representantes de algumas dessas variantes. 
Em trabalho mais recente, Ramirez (2010), ao fazer estudos sobre a família Txapakúra, descreve o agrupamento genético sobre essa família, com base em comparações estatísticas de aproximação percentual de dados lexicais, como se pode verificar na Figura 1, registrada em seguida.

Figura 1 - Esquema da organização da relação genética do Txapakúra ${ }^{8}$.

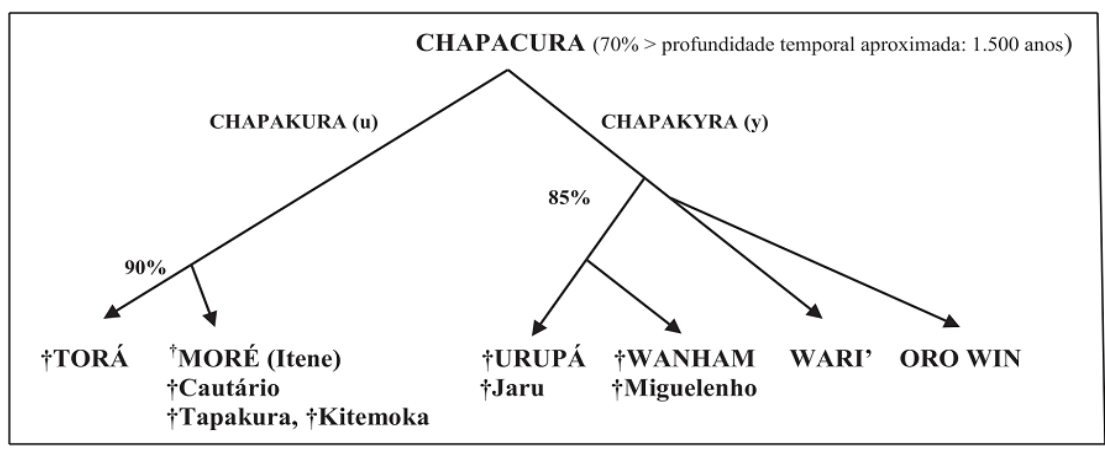

Fonte: Ramirez (2010:187).

Com base em literaturas disponíveis (Rodrigues 2002, Ramirez 2010, Aikhenvald e Dixon 1999a, Everett e Kern 2006) a língua Oro Waram Xijein é um dialeto pertencente ao subgrupo 'Wari', que por sua vez, forma um subramo mais próximo com o Oro Win, que por sua vez se relaciona geneticamente com outras oito línguas, quase todas já desaparecidas.

Hoje os Oro Waram Xijein vivem parte com os Oro Waram, na T.I. Igarapé Lage; parte com os Oro Mon, na T.I. Ribeirão e outros vivem na T.I. Sagarana. Em seguida mostramos, no Mapa 1, a T.I. e a aldeia em que parte de nossa pesquisa foi desenvolvida.

Figura 2 - Mapa $^{9}$ da localização da T.I e da aldeia Sagarana, no município de Guajará Mirim, RO.

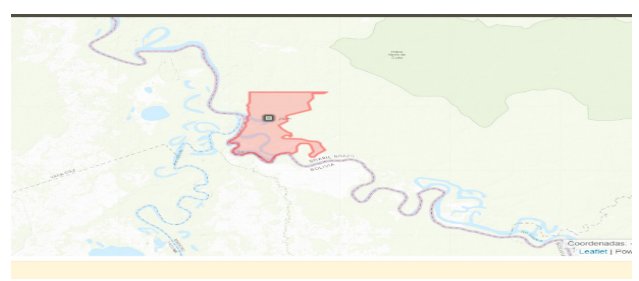

Fonte: Instituto Socioambiental - ISA (2020).

8 Ramirez (2010) adota a terminologia Chapacura, assim como Everett e Kern (2006), para se referir à família dessas línguas, porém adotamos a terminologia Txapakúra, como descrito por Rodrigues (2002), para o presente trabalho.

9 Disponível em: <https://terrasindigenas.org.br/pt-br/terras-indigenas/3853>. Acesso em: 28 de maio de 2020. 


\section{Sistema fonológico do Oro Waram Xijein}

Em uma perspectiva metodológica e descritiva à luz de princípios de Pike $^{10}(1943,1947)$ descrevemos para o Oro Waram Xijein treze (13) fonemas consonantais: as oclusivas /p, t, k, $\mathrm{P} /$; as fricativas $/ \mathrm{h}, \int$ ); as nasais $/ \mathrm{m}, \mathrm{n}, \mathrm{n} / ;$ o tep $/ \mathrm{f} /$ as aproximantes $/ \mathrm{w}, \mathrm{j} /$ e ainda, mesmo que pouco produtivo na língua, o trill (vibrante) / $\mathrm{ta}_{\mathrm{B}} /$. Descrevemos também cinco (5) fonemas vocálicos: os anteriores /i, e, y/; o central /a/ e o posterior /o/. Não há, neste dialeto, vogais fonologicamente nasais, mas há processo de nasalização, ou seja, variações fonéticas.

Com respeito à estrutura silábica, há as seguintes possibilidades fonológicas de realizações: CV, CVC, VC e V, sendo CV a forma proeminente na língua, conforme se verifica nos exemplos seguintes.

\begin{tabular}{|c|c|c|c|}
\hline 1) $\quad \mathrm{CV}$ & ['na] & /na/ & ‘1PS’ \\
\hline $\mathrm{CVC}$ & ['jat'] & /jat/ & 'dente' \\
\hline $\mathrm{VC}$ & ['õm'] & /om/ & ‘negação’ \\
\hline V & [a.'wi] & /a.wi/ & 'bom, bem, gostoso' \\
\hline
\end{tabular}

Quanto ao acento, podemos destacar três premissas principais para o Oro Waram Xijein: (i) o acento sempre recai na última sílaba da palavra, como já descrito em outros trabalho para outras variantes do Txapakúra (Apontes 2015, Sousa 2009, Maeda 2000); (ii) o acento não é fonológico e (iii) na posição de acento primário da sílaba, a vogal tende a se realizar com maior duração, o que é de certa forma comum a línguas do mundo, uma vez que o as vogais normalmente possuem maior duração quando acentuadas (Ladefoged 1975, Ladefoged e Maddieson 1996, Couto 2016), configurando-se, muitas vezes, em uma sílaba pesada (Hayes 1981, Couto 2016) e influenciado bastante o ritmo da língua.

Há ainda, nesta variante, realizações muito reduzidas das vogais e ou até mesmo o apagamento delas, o que também interfere na configuração das sílabas,

10 Pike Kenneth L. Pike foi o linguista americano que propôs metodologias a teorias (Pike 1943, 1947) para descrição estrutural do sistema fonético-fonêmico e as regras de realizações das variações fonéticas (alofônicas) das línguas. Entres essas premissas, destacam-se: a) os sons tendem a ser modificados por seus ambientes fonéticos; b) os sistemas de sons têm uma tendência à simetria fonética; c) os sons tendem a flutuar: se esta flutuação é entre segmentos não contrastivos, ela é estruturalmente não-significante e não deve, portanto, ser simbolizado em uma só transcrição fonêmica; d) sequências características de sons exercem pressão estrutural na interpretação fonológica de segmentos ou de sequências de segmentos suspeitos. 
criando estruturas fonéticas com grupos consonantais tautossilábicos, em ataque complexo, ou seja, realizações com duas consoantes no ataque (com respeito a outros estudos sobre estes fenômenos, ver Couto 2016, Apontes 2015), como se verifica nos exemplos seguintes.

5)

6)

$\left[{ }^{11}\right.$ kraw.a $] \sim\left[k^{\mathfrak{p}}\right.$ raw.a $]$

/ka.raw.a/ 'carne'

CV.CCV.CVC

/ta.pi.ri.ji?/

\section{'nossa pele'}

Em seguida (Tabela 2) descrevemos as principais restrições fonéticas dos segmentos da língua Oro Waram Xijein. Cabe informar ainda que as palavras no Oro Waram Xijein têm maior ocorrência no formato dissilábico e trissilábico, e, de forma menos produtivo, temos as monossilábicas e polissilábicas (com quatro ou mais sílabas). Os encontros consonantais, seja tautossilábicos seja heterossilábicos são evitados, porém ocorrem, mesmo que em número reduzido.

\section{Quadro 1 - Principais ocorrências e restrições fonéticas do Oro Waram Xijein.}

\begin{tabular}{|c|c|c|c|c|c|c|}
\hline $\begin{array}{l}\text { Em início } \\
\text { de sílaba e } \\
\text { de palavra } \\
\text { precedida de } \\
\text { silêncio (\#_). }\end{array}$ & $\begin{array}{l}\text { Em } \\
\text { início de } \\
\text { sílaba } \\
\text { medial } \\
\left(\$ \_\right) .\end{array}$ & $\begin{array}{l}\text { Em posição } \\
\text { de conda } \\
\text { intrassilábica } \\
\left(\$ \_\$\right) .\end{array}$ & $\begin{array}{l}\text { Em posição } \\
\text { de coda em } \\
\text { sílaba final } \\
\text { seguida de } \\
\text { silêncio } \\
(\text { \#). }\end{array}$ & $\begin{array}{l}\text { Em posição } \\
\text { de } C_{2} \text { em } \\
\text { estrutura } \\
\left(C_{1} C_{2} V\right) .\end{array}$ & $\begin{array}{l}\text { Em } \\
\text { posição } \\
\text { de } C_{1} \text { em } \\
\text { estrutura } \\
\left(C_{1} C_{2} V\right) .\end{array}$ & $\begin{array}{l}\text { Em } \\
\text { núcleo } \\
\text { silábico } \\
(\mathrm{N}) .\end{array}$ \\
\hline $\begin{array}{l}\text { Todas as } \\
\text { vogais e } \\
\text { consoantes. }\end{array}$ & 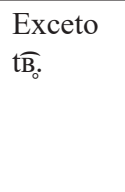 & $\begin{array}{l}\text { Todas as } \\
\text { vogais e as } \\
\text { consoantes } \\
\mathbf{w}, \mathbf{h} \text { e j. }\end{array}$ & $\begin{array}{l}\text { Todas as } \\
\text { vogais e as } \\
\text { consoantes. } \\
\text { Exceto } \widehat{\mathbf{t B}}_{\mathbf{8}}, \\
\text { f, h e } \int \text {. }\end{array}$ & $\begin{array}{l}\text { Somente o } \\
\text { tep } \mathbf{r} \text {. }\end{array}$ & $\begin{array}{l}\text { Somente } \\
\text { as } \\
\text { consoantes } \\
\mathbf{p}, \mathbf{t} \text { e } \mathbf{k} .\end{array}$ & $\begin{array}{l}\text { Somente } \\
\text { as } \\
\text { vogais. }\end{array}$ \\
\hline
\end{tabular}

O dialeto Oro Waram Xijein tem característica tipológica de língua isolante, ou seja, as funções morfológicas e sintáticas acontecem de forma mais produtiva fora da estrutura interna da palavra, contudo, há processos morfossintáticos, mesmo que poucos, que são marcadas na estrutura interna da palavra, principalmente para concordância de gênero. A título de exemplificação comparativa do que estamos argumentando aqui, podemos verificar dados do Manxineru (Aruák) e Xokleng/Laklãnõ (Macro-Jê), sendo respectivamente

11 Um dos fenômenos interessantes do sistema fonético e fonológico da língua Oro Waram Xijein são as sílabas com onset complexo, pois só ocorre com o apagamento vocálico e tendo o tep $(\mid)$ em posição de $\left(\mathrm{C}_{2}\right)$, ou seja, em estrutura $\left(\mathrm{C}_{1} \mathrm{I}_{2} \mathrm{~V}\right)$, além disso realizações reduzidas das vogais são mais comuns, que configura uma estrutura silábica $\left(\mathrm{C}_{1}{ }_{1} \mathrm{I}_{2} \mathrm{~V}\right)$. Em princípio não se trata nem de vogal de apoio (sem valor fonético e fonológico) nem de epêntese (inserção de vogal), mas realmente um caso de redução vocálica, em tese, para que o sistema adquira um ritmo próprio, caso análogo com que ocorre com a língua Manxineru (Aruaká) (Couto 2016). Sobre este ponto, a nossa hipótese coaduna, por exemplo, como Apontes (2015), este sobre a variante Oro Waram. 
consideradas aglutinante e isolante (cf. Couto 2016), e compará-las com o Oro Waram Xijein.

\section{Exemplo do Xokleng/Laklãnõ:}

7)

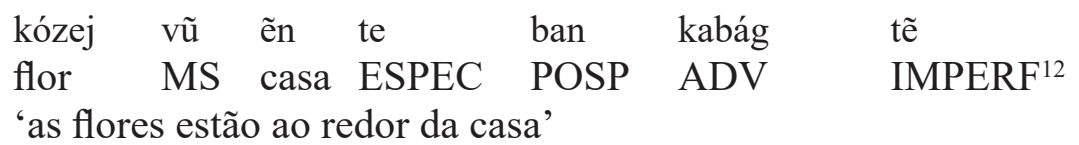

\section{Exemplo do Manxineru:}

8) ni-ka-li=hita $=$ ri-ni-ka-ni

comer-C.V-NMLZ= carne de caça=3S.M-comer-C.V-PROG ${ }^{13}$

'ele comerá carne de caça'

\section{Exemplos do Oro Waram Xijein:}

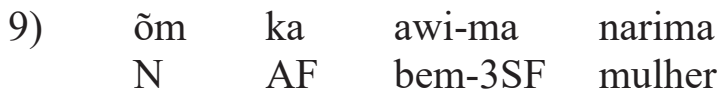

'a mulher não está bem'

10) õm ka awi-ka trama

$\mathrm{N}$ AF bem-3SM homem

'a mulher não está bem'

Como se observa, apesar de o Oro Waram Xijein possuir flexão de concordância de gênero e pessoa interna em algumas palavras, a língua está mais próxima de língua com características isolantes, como ocorre com a língua Xokleng/Laklãnõ.

\section{Inventário fonológico das consoantes}

Organizamos na Tabela 3 os fonemas consonantais do Oro Waram Xijein, conforme característica de classe natural, com especial atenção ao ponto e modo de articulação.

12 Glossa: $\mathrm{MS}=$ masculino singular; $\quad$ ESPEC=especificador; $\quad \mathrm{POSP}=$ posposição; $\mathrm{ADV}=$ advérbio; IMPERF=imperfectivo.

13 Glossa: $\mathrm{C} . \mathrm{V}=\mathrm{Classe}$ verbal; $\mathrm{NMLZ}=$ normalizador; $3 \mathrm{~S} . \mathrm{M}=$ terceira pessoa singular masculino; $\mathrm{PROG}=$ progressivo. 
Tabela 2 - Inventário fonológico das consoantes do Oro Waram Xijein.

\begin{tabular}{|l|c|c|c|c|c|c|}
\hline & Labial & Alvelar & Alveopalatal & Palatal & Velar & Glotal \\
\hline Oclusivo & $\mathbf{p}$ & $\mathbf{t}$ & & & $\mathbf{k}$ & $\mathbf{P}$ \\
\hline Vibrante (trill) & ${\widehat{\mathbf{t B}^{1}}}^{14}$ & & & & & \\
\hline Fricativo & & & $\mathbf{J}$ & & & $\mathbf{h}$ \\
\hline Tepe & & $\mathbf{f}$ & & & & \\
\hline Nasal & $\mathbf{m}$ & $\mathbf{n}$ & & $\mathbf{j}$ & & \\
\hline Aproximante & $\mathbf{w}$ & & & $\mathbf{j}$ & & \\
\hline
\end{tabular}

\section{Demonstrando contrastes}

Demonstramos, em seguida, por meio de pares mínimos e/ou análogos, contrastes que fundamentam a existência de treze (13) fonemas consonantais e cinco (5) fonemas vocálicos na língua Oro Waram Xijein.

Contrastes entre fonemas consonantais

Descrevemos, na perspectiva da linguística descritiva (Pike 1947, Jakobson 1939 entre outros), para o Oro Waram Xijein, treze (13) consoantes, sendo que elas se distinguem por ponto e modo de articulação e também por ausência ou presença de vibração das cordas vocálicas, quais sejam: quatro (4) consoantes obstruintes descontínuas (oclusivas), a labial /p/, a alveolar $/ \mathrm{t} /$, a velar $/ \mathrm{k} / \mathrm{e}$ a glotal / $/$ /; uma (1) vibrante, o trill bilabial /tą/; duas (2) fricativas, a alveolar / $/$ e a glotal /h/; uma (1) tep, a alveolar /r/; três (3) nasais, a bilabial $/ \mathrm{m} /$, a alveolar $/ \mathrm{n} /$ e a palatal $/ \mathrm{n} /$ e duas (2) aproximantes, a bilabial $/ \mathrm{w} /$ e a palatal $/ \mathrm{j} /$. Em seguida descrevemos os contrastes fonológicos.

$$
/ \mathbf{p} /: / \mathbf{w} /
$$

$\begin{array}{lll}\text { ['kap'] } & / \text { kap/ } & \text { 'lagarto' } \\ \text { ['kaw] } & / \text { kaw/ } & \text { 'comer' }\end{array}$

$$
/ \mathbf{p} /: / \mathbf{m} /
$$

\begin{tabular}{|c|c|}
\hline $\begin{array}{l}{\left[\mathrm{pi}^{\prime} \mathrm{kot}^{\top}\right]} \\
{\left[\mathrm{mi}^{\prime}{ }^{\prime} \mathrm{kpp}^{\top}\right.}\end{array}$ & $\begin{array}{l}\text { /pikot/ } \\
\text { /mikop/ }\end{array}$ \\
\hline
\end{tabular}

14 Conforme registrado por Apontes (2015:22): "Bèksta (1982:iii) descreve esse fonema como 'bilabial vibrante surda', grafando-o como $\{/ \tilde{\mathrm{p}} /\}$. Segundo Everett e Kern (2006:1):

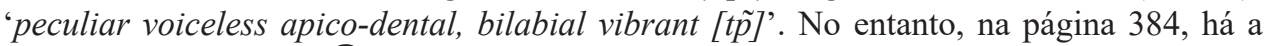
seguinte representação / $/$ B̊ $/$, afirmando que tal fonema é representado como "um alofone de $/ \mathrm{t}^{\mathrm{pà}} /$ em outros dialetos', e que ocorre somente diante de / / / e /oá/. Para mais detalhes sobre a realização desse fonema 'não usual', ver Ladefoged e Everett (1996). Depois, a descrição também foi publicada em Ladefoged (2001). Aikhenvald (2012:108) o considera 'um dos sons raros da região Amazônica'.” 
$/ \mathbf{t} /: / \mathbf{f} /$

13)

$\begin{array}{lll}{[\mathrm{a} \text { ' ra }]} & \text { /ara/ } & \text { 'fazer' } \\ {[\text { ha'ta }]} & \text { /hata/ } & \text { 'farinha de milho' }\end{array}$

$/ \mathbf{t} /: / \mathbf{n} /$

14)

$\begin{array}{lll}\text { ['kyn'] } & / \mathrm{kyn} / & \text { 'escorpião' } \\ {\left[{ }^{\prime} \mathrm{kyt}^{\prime}\right]} & / \mathrm{kyt} / & \text { 'pegar' }\end{array}$

$/ \mathbf{t} /: / \mathbf{k} /$

15) ['kyn'] /kyn/ 'escorpião'

['tyn'] /tyn/ 'cabelo'

$/ \mathbf{k} /: / \mathbf{h} /$

16) [uri'ko] /oriko/ 'ele'

[kot'sa'ho] /kotaraho/ 'galinha'

$/ \mathbf{k} /: / \mathbf{p} /$

17)

$\begin{array}{lll}{\left[{ }^{\prime}{ }^{\prime}{ }^{\prime}\right]} & / \text { tok/ } & \text { 'olho' } \\ \text { ['top'] } & / \text { top/ } & \text { 'colher (verbo)' }\end{array}$

$/ \mathbf{l} /: / \mathbf{k} /$

18) [wa'ta? $]$ wata?/ 'PS'

['ẽm 'tak'] /em tak/ 'sucuri'

$\widetilde{\mathbf{t B}} /: / \mathbf{t} /$

['trĩm] /trim/ 'casa'

$\widetilde{\mathbf{t B}_{0}} /: / \mathbf{m} /$

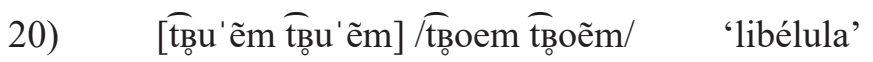
['mbe ${ }^{\mathrm{e}} \mathrm{e}$ ] $/ \mathrm{merem} /$ 'gritar' 


$$
/ \mathbf{j} /: / \mathbf{j} /
$$

21)

$\begin{array}{lll}{[\text { 'jat'] }} & / \text { jat/ } & \text { 'dente' } \\ {[\text { 'Jak'] }} & / \text { Jak/ } & \text { 'chupar' }\end{array}$

$/ \mathbf{h} /: / \mathbf{j} /$

22)

\begin{tabular}{|c|c|}
\hline 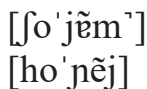 & $\begin{array}{l}\text { /Sojam/ } \\
\text { /honej/ }\end{array}$ \\
\hline
\end{tabular}

$$
/ \mathbf{n} /: / \mathbf{r} /
$$

23)

$\begin{array}{lll}{[\mathrm{a} ' \mathrm{ra}]} & / \mathrm{a} \text { 'ra/ } & \text { 'fazer' } \\ {[\text { 'na }} & / \text { 'na/ } & \text { 'eu' }\end{array}$

$$
/ \mathbf{n} /: / \mathbf{n} /
$$

24)

$\begin{array}{lll}\text { [pa'na] } & \text { /pana/ } & \text { 'árvore' } \\ \text { [paj'na] } & \text { /pajna/ } & \text { 'boca, minha boca' }\end{array}$

25)

$/ \mathbf{j} /: / \mathbf{t} /$

$\begin{array}{lll}{[\text { 'jat'] }} & / \text { jat } / & \text { 'dente' } \\ {\left[\text { ka'tat' }^{\prime}\right.} & / \text { katat } / & \text { 'seio' }\end{array}$

$/ \mathbf{t} /: / \mathbf{k} /$

26)

$\begin{array}{lll}{[\text { [i'ki: }]} & / \text { jiki/ } & \text { 'traíra' } \\ {\left[\mathrm{pi}{ }^{\prime} \mathrm{ti}\right]} & / \mathrm{piti} / & \text { 'mosquito preto' }\end{array}$

\section{Particularidades alofônicas das consoantes}

A proposta para esta seção é descrevemos os ambientes, inclusive com suas respectivas restrições fonotáticas, de ocorrência de alofones de fonemas consonantais do Oro Waram Xijein. Metodologicamente, descrevemos os ambientes, iniciado pelas posições na estrutura silábica, seguida da posição na palavra, informando primeiramente o dado fonético, depois o fonológico, seguido de tradução.

\section{O fonema /p/}

O fonema oclusivo bilabial surdo $/ \mathrm{p} /$ possui três fones [p], [p'] e [ph $\mathrm{p}^{\mathrm{h}}$. O fone [p] poder ocorrer em qualquer posição de palavra, e com qualquer vogal, 
desde que não seja no final de sílaba e palavra. Já o fone [p'] (não explodido/ sem soltura) só ocorre em posição de coda em final de palavra.

\section{Exemplos de ocorrências do fone [p]:}

27) [pipi'ta]

/pipita/

'piranha'

28) [oropa' pat'] $^{\top}$

/oropapat/

'aranha'

29) $\quad\left[\mathrm{k}^{\mathrm{p}} \mathrm{ra} \mathrm{pa} \mathrm{k}^{\mathrm{p}} \mathrm{ra} \mathrm{pa}\right]$

/karapa karapa/

'pacu (esp. de peixe)'

\section{Exemplos de ocorrências do fone [ $\left.p^{\top}\right]$ :}

30) [mi'rop'] /mirop/ 'macaco parauacu'

31) [a'hop'] /ahop/ 'jacaré'

\section{$O$ fonema $/ \mathbf{k} /$}

$\mathrm{O}$ fonema $/ \mathrm{k} /$ possui quatro alofones $[\mathrm{k}],\left[\mathrm{k}^{\mathrm{w}}\right],\left[\mathrm{k}^{ }\right] \mathrm{e}\left[\mathrm{k}^{\mathrm{h}}\right]$. O fone $[\mathrm{k}]$ ocorre em qualquer posição da palavra em onset silábico e com qualquer vogal. $\mathrm{O}$ fone labializado $\left[\mathrm{k}^{\mathrm{w}}\right]$ ocorre somente quando seguida de vogal posterior. Já o fone $\left[\mathrm{k}^{`}\right]$ só ocorre em final de sílaba e palavra seguida de silêncio. Trataremos do fone $\left[\mathrm{k}^{\mathrm{h}}\right]$ mais adiante.

Exemplos de ocorrências do fone [k]:

[ka'ti]

/kati/

'doente'

$$
\text { [tak'ara'ĩn’] }
$$

/takarain/

'beira (do rio)'

34)

$$
\text { [kopa'kaw] }
$$

/kopakaw/

'onça'

Exemplos de ocorrência do fone $\left[k^{w}\right]$ :

['k $\left.{ }^{\mathrm{w}} \tilde{\mathrm{em}}{ }^{\top}\right]$

36)

37) /koam/ 'boró'

/pat tokoine/ 'meus rins'

/paSokoa/ 'jatobá' 


\section{Exemplos de ocorrências do fone [ $k$ ']:}

['ky 'ky ryk'] / /ky kyryk/ 'ralar'

39) [hi' 'rik']

/hirik/

'ver'

\section{O fonema $/ \mathbf{t} /$}

$\mathrm{O}$ fonema / $\mathrm{t} /$ possui quatro fones $[\mathrm{t}],\left[\mathrm{t}^{ }\right],[\mathrm{t}],[\mathrm{J}]$. O fone $[\mathrm{t}]$ ocorre em qualquer ambiente da palavra, com qualquer vogal em posição de onset. Já o [ $\left.\mathrm{t}^{\top}\right]$ só ocorre em posição de coda no final de palavra. Tratarem dos fones [t'] e [S] mais adiante.

\section{Exemplos de ocorrências do fone [t]:}

\begin{tabular}{|c|c|c|c|}
\hline 40) & [tiki'pẽn’] & /tikipan/ & 'tatu canastra' \\
\hline & {$\left[\mathrm{k}^{\mathrm{p}}\right.$ rato $\left.\mathrm{k}^{\mathrm{w}} \mathrm{e}\right]$} & /karatokoe/ & 'castanheira' \\
\hline 42) & [tama'tẽn'] & /tamatan/ & 'batata (batata doce)' \\
\hline
\end{tabular}

\section{Exemplos de ocorrência do fone $\left[t^{\top}\right]$ :}

$\begin{array}{llll}\text { 43) } & {\left[\mathrm{ji}^{\prime} \text { tot }^{\prime}\right]} & / \text { Sitot/ } & \text { 'roça' } \\ 44) & {\left[{ }^{\prime} \mathrm{ty}^{\mathrm{t}}\right]} & / \text { tyt/ } & \text { 'andar' }\end{array}$

\section{O fonema / $/$}

O fonema oclusivo glotal / $/$ / possui apenas o fone [?], que pode ocorrer em qualquer posição da palavra.

\section{Exemplos de ocorrências do fone [?]:}

$\begin{array}{llll}45) & \text { [me'te? } & \text { /mete?/ } & \text { 'minhoca' } \\ 46) & \text { [ko't're? } & \text { /kotere?/ } & \text { 'deus' } \\ 47) & \text { ['pa? }] & \text { /pa?/ } & \text { 'matar' } \\ 48) & \text { ['wa? 'ki 'na }] & \text { /wa? ki na/ } & \text { 'eu cheguei' } \\ 49) & \text { ['he '?e }] & \text { /'he '?e/ } & \text { 'sim' }\end{array}$




\section{O fonema $/ \widehat{\text { tBo }} /$}

O fonema $/ \widehat{t_{B}} /$ possui apenas o fone $\left[\widehat{\mathrm{tB}_{0}}\right]$, que ocorre somente em início de palavra e com vogais altas. Essa consoante é extremamente rara nas línguas pelo mundo (Everett e Kern 2006, Apontes 2015, Ladefoged 2001, Ladefoged e Everett 1996, Aikhenvald e Dixon 1999a) como já apontado anteriormente neste trabalho.

Segundo consta na literatura a respeito, como em Ladefoged e Everett (1996), o primeiro autor a registrar este fonema foi Royal Taylor (1975). Para Ladefoged e Everett (1996):

A maioria dos sons pode ser descrito em termos de um conjunto padrão de características fonológicas, ou em termos de valores de parâmetros fonéticos bem conhecidos. Mas algumas línguas, particularmente as línguas ameaçadas de extinção menores do mundo, também contêm muitos sons incomuns que testar nossas teorias descritivas tradicionais. Um exemplo é a plosiva dental seguida por um trinado bilabial, encontrado nas línguas Txapakúra. Sugerimos que haja um conjunto (com limites difusos) de sons mais comuns que participam de uma ampla gama de processos linguísticos e outro conjunto de sons mais raros que foram observados em apenas um ou duas línguas. (Ladefoged e Everett 1996:794) ${ }^{15}$.

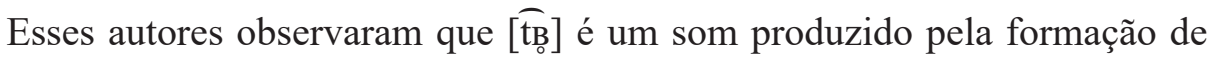
uma parada dentária, seguida de soltura, permitindo a explosão de ar que ocorre quando este é liberado de forma que os lábios ficam em vibração, como na

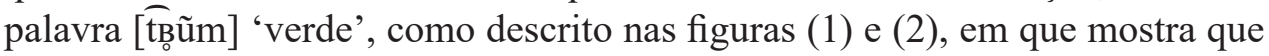
há contato lingual total nos dentes superiores e a na parte frontal dos alvéolos.

15 Do original: Most sounds can be described in terms of a standard set of phonological features, or in terms of values of well-known phonetic parameters. But some languages, particularly the smaller endangered languages of the world, also contain many unusual sounds that test our traditional descriptive theories. An example is the dental plosive followed by a bilabial trill, found in the Chapakuran languages. We suggest that there is a set (with fuzzy boundaries) of more common sounds that participate in a wide range of general linguistic processes and another set of rarer sounds that have been observed in only one or two languages. (Ladefoged e Everett, 2015, 794). 


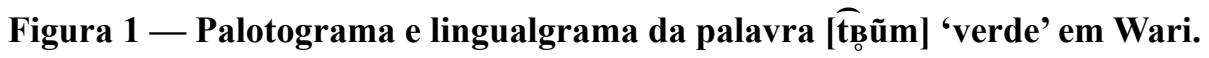
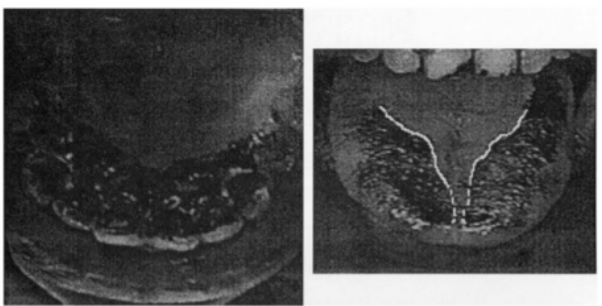

Fonte:Ladefoged e Everett $(1996,795)$.

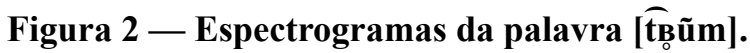

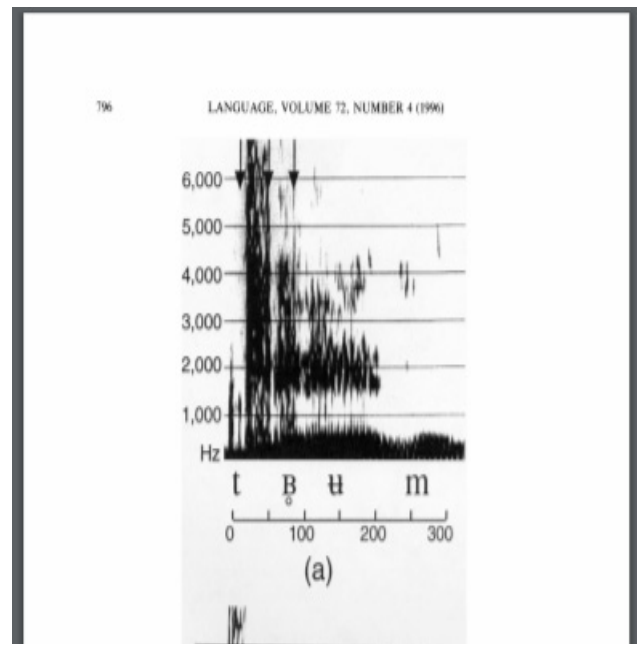

Fonte: Ladefoged e Everett (1996:796).

Como exemplificado por Ladefoged e Everett (1996), na área entre as linhas brancas tracejadas na Figura 1, a parte da língua na linha média mais para trás na lâmina mostra que não há contato com a parte superior do palato, sendo que o formato da lâmina e do ápice da língua proporciona a formação de um jato estreio na medida em que o ar é liberado. Já no espectrograma, Figura 2, as setas indicam o resultado acústico provocado pelas vibrações dos lábios, que estão ligeiramente separados, até que haja o fechamento completo, seguido de soltura (explosão). Essa característica acústica e provocada principalmente pela abertura e fechamento rápido dos lábios.

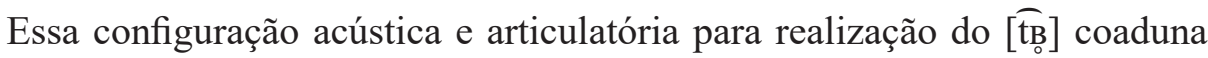
com que afirmam Ladefoged e Maddieson $\left(1996^{16}\right)$, pois para os autores a

16 Do original: The primary characteristic of a trill it is the vibration of one speech organ against another, driven by the aerodynamic conditions. One of the soft moveable parts of the vocal tract is placed close enough to another surface, so that hen a current of air of the right strength passes through the aperture created by this configuration, a repeating pattern of closing and opening of the flow channel occurs (Ladefoged e Maddieson 1996, 217). 
principal característica de um trill é a vibração de um órgão da fala contra outro, impulsionada pelas condições aerodinâmicas. Uma das partes móveis e macias do trato vocal é colocada perto o suficiente de outra superfície, de modo que quando uma corrente de ar da força direita passa através da abertura criada por essa configuração, ocorre um padrão repetitivo de fechamento e abertura do canal de fluxo.

Assim, como já adotado em outros trabalhos sobre o subgrupo Warí, como Apontes (2015), adotamos o símbolo fonético [ [t] $]$ para ser referir ao fonema (trill) bilabial vibrante apical surdo.

\section{Exemplos:}

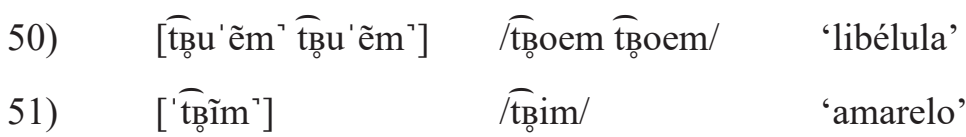

\section{O fonema $/ \mathrm{j} /$}

O fonema / $/$ / possui apenas o fone [J]. Esse fone ocorre apenas em onset, mas em qualquer lugar da palavra e com qualquer vogal.

\section{Exemplos de ocorrência do fone [J]:}

[Si'ki:]

53)

54)

$$
\text { [pafu'k }{ }^{\mathrm{w} a} \text { ] }
$$

[pa'跑']
/ jiki/

/pasokoa/

/pasam/ 'traíra'

'jatobá'

'pica pau'

\section{O fonema $/ h /$}

$\mathrm{O}$ fonema $[\mathrm{h}]$ possui dois fones $[\mathrm{h}]$ e [h]. $\mathrm{O}$ fone $[\mathrm{h}]$ ocorre em qualquer posição da palavra desde que em onset silábico. Já o seu homorgânico vozeada [€], somente ocorre entre sons vozeados, principalmente entre vogais.

\section{Exemplos de ocorrência do [h]}

$$
\text { [hũma'y] }
$$

[naha' $\left.\mathrm{rak}^{\prime}\right]$

[pete'het'] /homay/

/naharak/

/petehet/ 'filhos/filhas'

'mato'

'língua' 


\section{Exemplos de ocorrência do [h]:}

['pa 'nõn 'fr̃m]

59)

['kafii 'wa]

/pa non ham/

'eu pesquei o peixe'

/kahi wa/

'gripe'

\section{O fonema $/ \mathbf{r} /$}

$\mathrm{O}$ fonema $/ \mathrm{f} /$ possui apenas o fone $[\mathrm{r}]$. Esse fone é mais produtivo em posição de onset de sílaba simples ${ }^{17}$, em qualquer posição da palavra e com qualquer vogal, mas também pode ocorrer como $\mathrm{C}_{2}$ de onset complexo, contudo para isso acontecer a vogal da sílaba anterior é deletada, forma esta que é muito rara na língua, o que a torna sem mora silábica, assim o tep se ressilabifica, ocorrendo, dessa forma, como $\mathrm{C}_{2}$ da sílaba precedente, se tornando ataque (onset) complexo.

\section{Exemplos de ocorrência do [r]:}

60) [oru'a]

61) $\left[\mathrm{t}^{\mathrm{e}} \mathrm{re} \mathrm{e}^{\prime} \mathrm{re}\right] \sim[$ tre' re $]$

62) [to'raw

63) $\quad\left[k^{\mathfrak{v}}\right.$ rapi'ta $] \sim[$ krapi 'ta $]$

64) $\quad\left[\operatorname{kot}^{\mathrm{p}} \mathrm{ra}\right.$ 'ho $] \sim[$ kotra' ho $]$

65) $\left[\right.$ ko' te $^{\mathrm{e}} \mathrm{e}$ ? $] \sim\left[\mathrm{ko}\right.$ 'tre? $\left.^{2}\right]$ loroa/ 'lama'

/terere/ 'borboleta'

/toraw/ 'papagaio'

/karapita/ 'veia (minha veia)'

/kotaraho/ 'galinha'

/kotere?/ 'deus'

\section{O fonema $/ \mathrm{m} /$}

O fonema $/ \mathrm{m} /$ possui quatro fones $[\mathrm{m}],\left[\mathrm{m}^{\urcorner}\right],[\mathrm{m} \mathrm{b}]$ e $[\mathrm{b}]$. O fone $[\mathrm{m}]$ ocorre só onset e em qualquer lugar da palavra e com qualquer vogal. $\mathrm{O}$ fone $\left[\mathrm{m}^{\urcorner}\right]$ocorre somente em posição final de sílaba e de palavra.

\section{Exemplos de ocorrências do fone [m]:}

$$
\text { [mi'kop'] /mikop/ 'paca' }
$$

17 As sílabas do Oro Waram Xijein podem ser foneticamente simples ou complexas. A sequência $\mathrm{CV}$ é uma sílaba simples, também chamada de aberta devido à ausência da coda. As demais, CCV, CCVC, CVC etc. são caracterizadas como complexas e/ou ramificadas a depender a corrente linguística. 
67) [my'mỹm'] /mymym/ 'pato'

68) $\quad[\mathrm{ka} ' \mathrm{mu}] \quad / \mathrm{kamo} / \quad$ 'jacu'

69) [ka'nõm] / $]$ kanom/ 'garganta'

\section{Exemplos de ocorrências do fone [m`]:}

70) ['ẽm'] /em/ 'cobra'

71) ['k $\left.\mathrm{k}^{\mathrm{w}} \tilde{\mathrm{em}}{ }^{\top}\right] \quad / \mathrm{koam} / \quad$ 'boró'

\section{O fonema $/ \mathbf{n} /$}

O fonema $/ \mathrm{n} /$ possui quatro fones [n], [n'], [nd] e [d]. O fone [n] é ocorre em onset de qualquer sílaba e com qualquer vogal. $\mathrm{O}$ fone [n'] só ocorre em coda de sílaba final.

\section{Exemplos de ocorrência do fone [n]:}

72)

$\begin{array}{lll}{\left[\text { no'n'] }^{\prime}\right.} & / \text { non/ } & \text { 'abacaxi' } \\ {[\text { pr̃na'wo }]} & / \text { panawo/ 'lua' }\end{array}$

74) [ [t rawa'na] [ [ $\mathrm{t}^{\mathrm{p}}$ rawa'na] /tarawana/ 'fígado (meu fígado)'

\section{Exemplos de ocorrência do fone [n`]:}

75)

$$
\text { [no'mon'] /nomon/ 'anus' }
$$

76) ['tỹn'] /tyn/ 'cabelo'

\section{O fonema $/ \mathbf{n} /$}

O fonema $/ \mathrm{n} /$ possui apenas o fone $/ \mathrm{n} /$, que ocorre diante de qualquer vogal e em qualquer posição na palavra desde que na posição de onset.

\section{Exemplos de ocorrência do fone [n]:}

$$
\text { ['new] }
$$

/new/

'avô'

78)

$$
\text { ['tẹ̃] }
$$

$/ \tan /$

'marcador de futuro'

79)

$$
\text { [aj'ni?] /ajni?/ }
$$$$
\text { 'irmão mais velho' }
$$ 


\section{O fonema $/ \mathbf{w} /$}

$\mathrm{O}$ fonema /w/ possui apenas um fone, o [w], que nunca exerce o núcleo de sílaba. Esse fone pode ocorrer tanto na posição de onset quanto de coda e em qualquer posição da palavra.

\section{Exemplos de ocorrência do fone [w]:}

$\begin{array}{llll}\text { 80) } & \text { [wa'ri] } & \text { /wari/ } & \text { 'gente' } \\ 81) & \text { [horowaj'i] } & \text { /horowaji/ } & \text { 'verde (relativo à fruta)' } \\ 82) & {[\text { nẽna'wĩn'] }} & \text { /nanawin/ } & \text { 'céu' } \\ 83) & {[\text { waw'Jok'] }} & / \text { wawJok/ } & \text { 'macaco zogzog' } \\ 84) & {[\text { kopa'kaw }]} & / \text { kopakaw/ } & \text { 'onça' }\end{array}$

\section{O fonema $/ \mathbf{j} /$}

$\mathrm{O}$ fonema $/ \mathrm{j} /$ possui dois fones, o [j] e [i]. O fone [j] corre em qualquer lugar da palavra, mas nunca ocupando o núcleo silábico e ocorrendo sempre em junção a uma vogal, que inerentemente ocupa o núcleo da sílaba.

\section{Exemplos de ocorrência do fone $[j]$ :}

\begin{tabular}{|c|c|c|c|}
\hline 85) & [ja'kat'] & /jakat/ & 'pênis' \\
\hline 86) & [paja'mi 'wa] & /pajami wa/ & 'facão \\
\hline 87) & [wara'jy] & /warajy/ & 'brincar' \\
\hline 88) & [kaj'na] & /kajna/ & 'filha' \\
\hline 89) & [tohoj' '̌̃n'] & /tohojan/ & 'jatuarana' \\
\hline 90) & [ho'maj] & /homaj/ & 'gordura' \\
\hline
\end{tabular}

\section{Inventário fonológico das vogais}

Nessa seção descrevemos e analisamos os fonemas vocálicos do Oro Waram Xijein e suas implicações fonéticas e fonológicas no sistema linguístico dessa língua. Como forma metodológica, primeiramente descrevemos o inventário fonológico, conforme descrito na Tabela 3, e posteriormente elencamos os contrastes seguido das realizações alofônicas dos fonemas. 
Tabela 3 - Inventário fonológico das vogais do Oro Waram Xijein.

\begin{tabular}{|c|c|c|c|c|}
\hline & \multicolumn{2}{|c|}{ Anterior } & Central & Posterior \\
\hline & $\begin{array}{c}\text { Não } \\
\text { arredondado }\end{array}$ & Arredondado & $\begin{array}{c}\text { Não } \\
\text { arredondado }\end{array}$ & Arredondado \\
\hline Alto & $\mathrm{i}$ & $\mathrm{y}$ & & \\
\hline Médio & $\mathrm{e}$ & & & $\mathrm{o}$ \\
\hline Baixo & & & $\mathrm{a}$ & \\
\hline
\end{tabular}

\section{Contrastes dos segmentos vocálicos do Oro Waram Xijein:}

$/ \mathbf{i} /: / \mathbf{e} /$

92)

$\begin{array}{lll}{[\text { 'mi }]} & / \mathrm{mi} / & \text { 'mato' } \\ {\left[{ }^{\prime m e}\right]} & / \mathrm{me} / & \text { 'pássaro' }\end{array}$

$/ \mathbf{i} /: / \mathbf{y} /$

92)

$\begin{array}{lll}\text { ['hyk'] } & \text { /hyk/ } & \text { 'puxar' } \\ \text { ['hi] } & \text { /hi/ } & \text { 'gripe, resfriado' }\end{array}$

$/ \mathbf{a} /: / \mathbf{e} /$

93)

$\begin{array}{lll}\text { [a'pa?] } & \text { /apa?/ } & \text { 'avó' } \\ \text { [a'pe?] } & \text { /ape?/ } & \text { 'fome' }\end{array}$

$/ \mathbf{a} /: / \mathbf{0} /$

94)

$\begin{array}{lll}{\left[\mathrm{a}^{\prime} \mathrm{kop}^{\prime}\right]} & \text { /akop/ } & \text { 'mandioca' } \\ {\left[\mathrm{a}^{\prime} \mathrm{kap}^{\top}\right]} & \mathrm{kap} / & \text { 'lagarto' }\end{array}$

/e/ : /y/

95)

$\begin{array}{lll}\text { ['me }] & / \mathrm{me} / & \text { 'pássaro' } \\ {[\text { 'my }} & / \mathrm{my} / & \text { 'minha mão' }\end{array}$




\section{Particularidades alofônicas das vogais}

Inicialmente cabe informar que todas as vogais do Oro Waram Xijein têm variedades fonéticas alongadas e variedades reduzidas, além de variedades nasalizadas, mas essas são somente realizações fonéticas não se configurando, dessa forma, como fonema na língua. Salientamos também que a adjacência a consoantes nasais não obriga a realização nasal, como verificado em nossa pesquisa, pois há casos em que a vogal, mesmo em ambiente nasal, ocorre sem nenhum traça nasal, ou seja, a nasalização não é um processo obrigatório. Contudo, quando ocorre, é pelo processo de nasalização regressiva em virtude de posição adjacência dessa vogal a um som naturalmente nasal, que propaga o traço de nasalidade para essas vogais.

Já as vogais alongadas ocorrem em posição de acento principal da palavra ou como forma de ênfase. Também encontramos realizações de vogais extremamente reduzidas, estas só ocorrendo em contexto $\left(\mathrm{C}_{1}-\mathrm{C}_{2}\right)$, em que $\left(\mathrm{C}_{2}\right)$ seja o tep /r/. Para essas realizações, há de se fazer um estudo mais aprofundado com uso da técnica e metodologia da fonética experimental para verificar esse fenômeno com melhores detalhes, pois só de oitiva nem sempre fica evidente, mesmo que o foneticista seja experiente (Ladefoged 1975). A mesma atenção se aplica às vogais alongadas e reduzidas para garantir riqueza de detalhes sobre o fenômeno, o que não foi possível de ser realizado para essa primeira investigação de trabalho preliminar.

\section{O fonema $/ \mathbf{i} /$}

$\mathrm{O}$ fonema /i/ possui dois fones [i], [ĩ]. O fone [i] ocorre em qualquer posição da palavra e com qualquer consoante. $\mathrm{O}$ fone [ĩ] só ocorre seguidas de consoantes nasais.

\section{Exemplos de ocorrência do fone [i]:}

$\begin{array}{ll}{\left[\mathrm{pi}{ }^{\prime} \mathrm{we}\right]} & \text { /piwa/ 'cutia' } \\ {[\text { oromi'jak'] }} & / \text { oromijak/ 'cachorro' } \\ {[\text { pi'ti] }} & / \text { piti/'mosquito preto' }\end{array}$

\section{Exemplos de ocorrência do fone [ĩ]:}

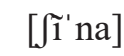

/ Jina/

'sol'

100) [ka'tĩm’]

/katim/

'pé (também pode designar dedo)' 


\section{O fonema /e/}

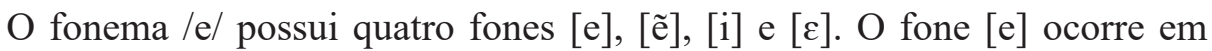
qualquer posição da palavra e adjacente a qualquer consoante, exceto trill. $\mathrm{O}$ fone [ẽ] só ocorre em adjacência a consoantes nasais, no processo de assimilação regressiva. $\mathrm{O}$ fone [i] ocorre somente em final de palavra em variação livre. $\mathrm{O}$ fone $[\varepsilon]$, apesar de pouco produtivo, ocorre em qualquer posição da palavra e com qualquer consoante, menos com o trill / $\mathrm{tr}_{\mathrm{B}} /$, na condição de variação livre com [e].

\section{Exemplos de ocorrência do fone [e]:}

$\begin{array}{llll}\text { 101) } & {[\text { pete'het'] }} & \text { /petehet/ } & \text { 'língua' } \\ \text { 102) } & {[\text { tere're }]} & / \text { terere/ } & \text { 'borboleta' } \\ 103) & {[\mathrm{ku} \text { ' } \mathrm{ew}]} & / \mathrm{kofew} / & \text { 'macaco de cheiro' }\end{array}$

\section{Exemplos de ocorrência do fone [ẽ]:}

$\begin{array}{llll}\text { 104) ['hẽg'] } & \text { /hen/ } & \text { '3PL, vocês' } \\ \text { 105) [kotẽ'ne] } & \text { /kotene/ } & \text { 'grande (largo, comprido)' } \\ \text { 106) [o'rẽm] } & / \text { orem/ } & \text { 'macaco guariba' }\end{array}$

\section{Exemplos de ocorrência do fone $[\varepsilon]$ :}

107) $\left[{ }^{\prime} \mathrm{pek}^{\top}\right] \sim\left[\right.$ 'pek$\left.^{\top}\right] \quad$ /oropek/ 'cérebro'

108) ['urE] [ ['ure 'kyn'] /ore kyn/ 'nariz dele'

\section{Exemplos de ocorrência do fone [i]:}

110) [tu»kwi $] \sim[$ tu»kwe $] \quad$ /tokwe/ 'castanheira'

\section{O fonema /y/}

$\mathrm{O}$ fonema $/ \mathrm{y} /$ possui dois fones $[\mathrm{y}]$ e $[\tilde{y}]$. O fone $[\mathrm{y}]$ ocorre em qualquer posição da palavra e com qualquer consoante, exceto com trill / / 
[ỹ] ocorre somente em juntura a consoantes nasais, em processo de assimilação regressiva.

\section{Exemplos de ocorrência do fone [y]:}
111) [ky' $\left.\mathrm{k}^{\mathrm{y}} \mathrm{ryk}^{\prime}\right] \quad$ /kykyryk/ 'periquito'
112) [kany'my] /kanymy/_ 'garganta', 'minha garganta'
113) [ty'ky] /tyky/ 'amarrar'

\section{Exemplos de ocorrência do fone $[\tilde{y}]$ :}

$\begin{array}{llll}114) & {[\text { 'ỹm'] }} & \text { /ym/ } & \text { 'mão' } \\ 115) & {[\text { kanỹ'my }]} & \text { /kanymy/ } & \text { 'minha garganta' } \\ 116) & {[\text { kotẽ'ne pa'kỹn'] }} & \text { /kotene pakyn/ } & \text { 'pedra grande' } \\ 117) & {[\text { mỹ'ny }]} & \text { /myny/ } & \text { 'abdômen' }\end{array}$

\section{O fonema $/ \mathbf{a} /$}

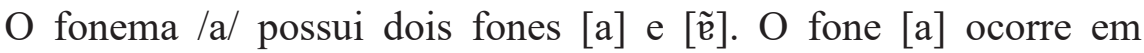
qualquer posição da palavra e adjacente a qualquer consoante, exceto trill / $\widetilde{\mathrm{t}_{\mathrm{B}}} / . \mathrm{O}$ fone $[\tilde{\mathfrak{e}}]$ ocorre apenas na juntura com consoantes nasais, em processo de assimilação regressiva.

\section{Exemplos de ocorrência do fone [a]:}

$\begin{array}{llll}\text { 118) } & {[\mathrm{ka} \text { 'ti }]} & \text { /kati/ } & \text { 'doente' } \\ \text { 119) } & {\left[\text { mi'nak wata'k }{ }^{\mathrm{e}} \mathrm{rat}^{\prime}\right]} & \text { /minak watakarat/ } & \text { 'queixada' } \\ \text { 120) } & \text { [hõ'ma }] & \text { /homa/ } & \text { 'gordo' }\end{array}$

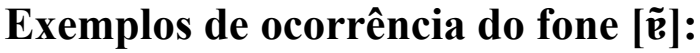

121) [pẽnaw'o] /panawo/ 'lua'

122) [tẽme'na] /tamana/ 'muito'

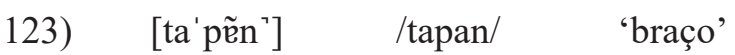




\section{O fonema /o/}

$\mathrm{O}$ fonema /o/ possui quatro fones [o], [õ], [u] e [ũ]. O fone [o] ocorre em qualquer posição da palavra e com qualquer consoante, exceto seguida por nasais. $\mathrm{O}$ fone $[\mathrm{u}]$ ocorre livremente em alofonia com [o]. $\mathrm{O}$ fone [õ] ocorre apenas na juntura com consoantes nasais, em processo de assimilação regressiva, o mesmo ocorre com o fone [ũ].

\section{Exemplos de ocorrência do fone [o]:}

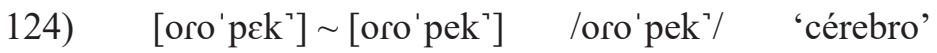

125) [paho'ho] /pahoho/ 'pulmão'

126) [ori'ko] /oriko/ 'ele'

Exemplos de ocorrência do fone [õ]:

127) [õm] $\quad /$ om/ 'negação (não)'

128) [nõ'nõn'] /nonon/ '3PL, ele'

129) [po'kõm] /pokom / 'nadar'

\section{Exemplos de ocorrência do fone [u]:}

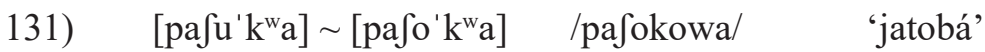

132) $\quad[\mathrm{k} \tilde{\mathrm{e}} \mathrm{nu}] \sim[\mathrm{k} \tilde{\mathrm{e}} \mathrm{\prime no}] \quad / \mathrm{kano} / \quad$ 'canoa'

\section{Exemplos de ocorrência do fone [ũ]:}

133) [hũn] /hon/ 'peidar'

134) [hũma'y] /homay/ 'filhos/filhas'

É importante ressaltar que, diferentemente de outros estudos sobre variantes desse subgrupo, como, por exemplo, Apontes (2015), para o Oro Waram, e Sousa (2009) para o Oro Mon, não verificamos a realização da vogal anterior 
média alta arredonda /Ø/, que é um dos pontos que difere o presente estudo desses outros.

\section{Principais processos fonológicos do Oro Waram Xijein}

Em seguida, descrevemos os principais processos fonológicos identificados nessa nossa primeira investigação no sistema do Oro Waram Xijein.

\section{Nasalização vocálica}

Todas as vogais da língua Oro Waram Xijein podem, por meio da propagação de nasalidade, se realizarem foneticamente como vogal nasalizada quando elas estão contíguas a consoantes nasais, no processo denominado de assimilação regressiva. Cabe informar, mesmo que o processe seja produtivo na língua, que a realização nasalizada não é obrigatória, como se verifica nos exemplos 137 e 138.

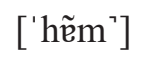

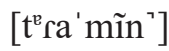

/ham/

taramin/

/mikon/

/kano ne hy/

/kanymy/ 'peixe'

'arara'

'mão dele'

'canoa de vocês'

'garganta', 'minha garganta'

\section{Redução vocálica ${ }^{18}$}

O que chamamos aqui de redução vocálica é o caso em que as vogais têm seu tempo de duração extremamente reduzido (Hayes 1981), como ocorre em outras línguas como o Manxineru (Aruák) (cf. Couto 2016), por exemplo, como podemos verificar nos dados seguintes.

18 Diferentemente do que ocorre em algumas línguas, como o português, por exemplo, que há uma epêntese, sem valor fonético ou fonológico nenhum, como vogal de apoio para a realização do tep [r] (ver Silveira 2007, Couto 2016), como em 'bºtoto' e 'p primo', na língua Oro Waram Xijein, a vogal tem seu tempo reduzido. Ou seja, a vogal já existe fonética e fonologicamente, o que permite a realização de onset complexo, uma vez que o valor da mora da vogal é reduzida significativamente (ver Hayes 1981) que sílabas de sequência CV.CV são interpretadas foneticamente como CCV. Um outro argumento para afirmarmos essa ocorrência é que o acento primário da língua, que sempre é na última sílaba, quando corre na sílaba com a vogal reduzida, é realizada no padrão $\mathrm{CCv}$ e não CV.CV, como, por exemplo em: /paka"rop/ (esp. de peixe) _ [pa" $\left.\mathrm{k}^{\mathrm{E}} \mathrm{rop}\right]$, em que o ritmo, e logicamente a posição do acento principal, é modificado com a ocorrência da redução e respectiva reorganização silábica. A esse respeito cabe aprofundamento nos estudos para melhores detalhes. 
140) [' $\left.\left.{ }^{\circ}{ }^{\circ o p}\right]\right] \quad$ lorop/ 'jenipapo'

141) [ta'pi $\left.\mathrm{p}^{\mathrm{i} i}\right] \quad$ /tapiri/ 'pele'

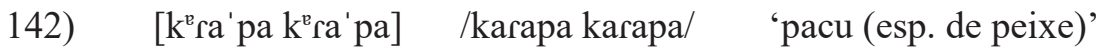

Vale ressaltar que estudo que lança mão da fonética acústica merece ser feito para aprofundar esse tema, por a fonética acústica contar com ferramentas e metodologias que ampliam a qualidade de verificação desses fenômenos (a esse respeito, ver Couto 2016, Barbosa e Madureira 2015, Ladeforged 1975).

\section{Alongamento vocálico}

O alongamento vocálico ocorre, de forma exclusiva, quando a vogal está em sílaba com acento primário. Cabe ressaltar que não é obrigatório o alongamento, mas quando ocorre, a exigência sistêmica é compor esse ambiente (Couto 2016).

143) ['wỹ:m'] /wym/ 'você'

144) ['kaw 'fi: ] /kaw Ji/ 'nós comemos'

145) [ka'mo:] $/ \mathrm{kamo} / \quad$ 'jacu (esp. de peixe)'

\section{Apagamento vocálico}

No dialeto Oro Waram Xijein, a vogal pode ocorrer não só de forma reduzida, como tratado anteriormente, mas também, mesmo que de ocorrência mais rara, o apagamento da vogal. Só foi possível verificar essa realização quando a sílaba seguinte está seguida do tep $/ \mathrm{r} /$, que se ressilabifica com a sílaba precedente, formando foneticamente, assim, um grupo consonantal em onset complexo como se verifica nos exemplos seguintes.

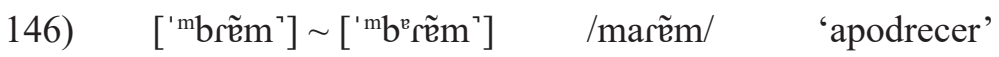

147) $\quad\left[\right.$ ta'pri] $\sim$ [ta'p' $\left.{ }^{\mathrm{i} i \mathrm{i}}\right] \quad$ /tapiri/ 'pele'

148) [kra'wa?] [k [ka'wa?] /karawa?/ 'caçar'

\section{Aspiração}

O processo de aspiração só ocorre, de forma mais perceptível, com as oclusivas $/ \mathrm{p} /$, /k/ e /t/, quando essas estão em final de sílaba e de palavra seguidas de silêncio, independentemente da vogal precedente. Quando não há aspiração, essas consoantes variam livremente na forma não explodida, que é extremamente mais comum ao sistema do Oro Waram Xijein. 


$\begin{array}{llll}\text { 149) } & \left.\text { [ja'kat }{ }^{\mathrm{h}}\right] & \text { /jakat/ } & \text { 'pênis' } \\ \text { 150) } & {\left[\mathrm{pa}^{\prime} \mathrm{pak}^{\mathrm{h}}\right]} & \text { /papak/ } & \text { 'milho' } \\ 151) & {\left[\text { 'top }^{\mathrm{h}}\right]} & \text { /top/ } & \text { 'colher (verbo)' }\end{array}$

\section{Laringalização}

A laringalização é um processo que merece atenção especial, por três principais motivos: (i) primeiro tem a ver com a larga ocorrência desse fenômeno no dialeto Oro Waram Xiejein, apesar da maior ocorrência adjacente a consoantes nasais e vogais; (ii) segundo é que esse fenômeno foi descrito em outras variantes do Txapakúra como fonema pós ou pré-laringalizado (Apontes 2015, Sousa 2009); (iii) terceiro porque muitas vezes esse fenômeno só se torna possível, pelo menos em nossa análise, de ser percebido, e assim descrito, com investigação da fonética acústica, por isso entendemos que esse fenômeno merece um estudo acústico mais aprofundado e com mais dados, inclusive com a ampliação do número de colaboradores falantes nativos, algo que não foi possível nesse recorte para esse primeiro trabalho.

Assim, entendemos, em princípio, em nossa análise preliminar da língua, que o processo de laringalização, assim como ocorre em outras línguas indígenas brasileiras, como Tupari (família Tupi-Tupari) e Sabanê (família Nambikwára), não é fonológica e não ocorre somente na junção a consoantes nasais, uma vez que verificamos vários dados com ocorrência fora desse contexto, como podemos verificar nos dados abaixo.

$\begin{array}{llll}\text { 152) } & \text { [ta' ki] } & \text { /taki/ } & \text { 'voar' } \\ 153) & \text { ['pan' 'na }] & \text { /pan na/ } & \text { 'eu caí' } \\ 154) & \text { [kotẽ'ne a'kõm'] } & \text { /kotene akom/ } & \text { 'rio grande' } \\ 155) & \text { [pa 'nõn 'hẽm'] } & \text { /pa non ham/ } & \text { 'eu matei o peixe' }\end{array}$

Como dito anteriormente, insistimos que estudos na área de fonética acústica (experimental) e os atuais avanços tecnológicos, que proporcionaram programas para análise de fala, têm permitido a possibilidade se verificar de forma mais rigorosa (empírica e experimentalmente) eventos linguísticos que até alguns anos atrás eram verificados ou percebidos somente com base na impressão auditiva dos estudiosos (Couto 2016, Ladefoged 1975, Ladefoged e Maddieson 1996). Assim, como informado anteriormente, muitas vezes não se percebe a laringalização, e outros fenômenos, apenas de oitiva (impressão auditiva), mas somente e/ou principalmente com o auxílio de recursos de software para a investigação acústica da fala, como o programa PRAAT, por exemplo. 


\section{Palatização}

O processo de palatalização na língua Oro Waram Xijein só foi verificado no fonema / $t /$, quando esse precede a vogal alta anterior não arredondada [i], ocorrendo assim duas possibilidades alofônicas, o [t] ou ainda o [J], havendo inclusive variação livre entre elas, como podemos verificar nos exemplos seguintes.

$$
\left[\mathrm{tij}^{\prime} r \mathrm{ry}\right] \sim\left[\mathrm{ji}^{\prime} r \mathrm{ry}\right] \quad / \mathrm{tiry} / \quad \text { 'minha casa' }
$$

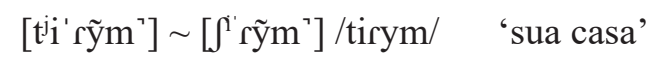

\section{Labialização}

Labialização em Oro Waram Xijein é uma variação fonética que só foi percebida em nossa pesquisa com fonema oclusivo velar $/ \mathrm{k} /$, quando este está seguido do /o/, e este seguido por outra vagal, o que acarreta uma restruturação silábica e rítmica, em que se tem fonologicamente duas sílabas e foneticamente se comporta como uma só, como percebido nos exemplos seguintes.

$$
\begin{array}{lll}
{\left[\text { to }^{\prime} \mathrm{k}^{\mathrm{w}} \mathrm{e}\right]} & \text { /tokoe/ } & \text { 'castanha' } \\
{\left[\text { to }^{\mathrm{w}}{ }^{\mathrm{w}} \tilde{\mathrm{e}}{ }^{\top}\right]} & / \text { tokoan/ } & \text { 'olho dela' } \\
{\left[\text { pat }^{\top} \text { tu' }^{\mathrm{w}} \mathrm{e}\right]} & / \text { pat tokoe/ } & \text { 'nome próprio' }
\end{array}
$$

\section{Pré-nasalização}

O que chamamos aqui de pré-nasalização é o processo em que as consoantes nasais $/ \mathrm{m} / \mathrm{e} / \mathrm{n} /$ se realizam em sílaba inicial e na posição de onset, como [ $\left.{ }^{\mathrm{m}} \mathrm{b}\right]$ e [ $\left.{ }^{\mathrm{n}} \mathrm{d}\right]$, em articulação complexa ${ }^{19}$, sendo $\mathrm{C} 2$ obrigatoriamente o tep [r]. Isso ocorre porque a vogal ou é apagada ou ocorre de forma muito reduzida, fincando imperceptível para o peso silábico (Couto 2016). Esses dois alofones nunca ocorrem em coda, conforme se verifica nos exemplos seguintes.

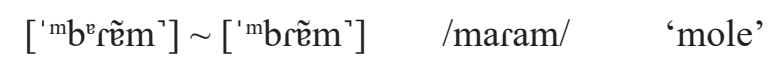

19 As consoantes consideradas com dupla articulação são aquelas que fonologicamente simples, mas que sua produção envolve duas articulações simultâneas, no caso das prénasalizadas, envolve duas oclusões, uma nos lábios e outra no levantando a língua em direção ao véu palatino (Odden 2005). Assim, o que se tem nessa produção é uma parte inicial nasal e uma parte final oclusiva (sempre sonora, no caso do Oro Waram Xijein), silabificadas no onset. Diferentemente de outras línguas (algumas línguas crioulas do Golfo da Guiné, por exemplo), que no começo de palavra, a parte nasal pode ser apagada, não encontramos essa realização na língua em análise (diferentemente do que descrito por Apontes 2015). 
162) ['mbisi 'na $] \sim$ ['mbri 'na $\quad$ / miri na/ 'eu moqueei'

163) [ ${ }^{\mathrm{n}}{ }^{\mathrm{o}}$ rõ'na $] \sim\left[{ }^{\mathrm{n}} \mathrm{d}\right.$ rõ'na $] \quad$ /norona/ 'eu olho'

164) ['mbõn'] $[$ bõn'] $\quad /$ mon/ 'fezes'

\section{Oralização}

No Oro Waram Xijein, os fonemas $/ \mathrm{m} / \mathrm{e} / \mathrm{n} /$, em raras realizações, podem ocorrer, em variação livre, de forma oralizada, se realizado, assim, simultaneamente como [b] e [d] em variação livre com [ $\left.{ }^{\mathrm{m} b}\right]$ e [ $\left.{ }^{\mathrm{n}} \mathrm{d}\right]$, ou seja, consoante soante nasal se realiza de forma obstruinte oral, como se vê em seguida.

$$
\left[\text { bõn }{ }^{\urcorner}\right] \sim\left[{ }^{\mathrm{m}} \mathrm{bõn}{ }^{`}\right]
$$

/mon/

'fezes'

$$
\left[\mathrm{d}^{\mathrm{o}} \text { rõ'na }\right] \sim\left[{ }^{\mathrm{n}} \mathrm{d}^{\mathrm{o}} \text { rõ'na }\right] \quad \text { /norona/ 'eu olho' }
$$

Como observado nessa seção, os processos fonológicos na língua em análise são muito produtivos e vários deles merecem uma investigação mais detalhada e com o uso da fonética experimental, algo que não foi possível fazer de forma enfática, detalhada e com metodologia e tempo de análise suficientes para essa análise preliminar do dialeto Oro Waram Xijein.

\section{Considerações finais}

Nossa pesquisa preliminar da língua Oro Waram Xijein, realizada também pela primeira vez por uma falante nativa da língua, nos permitiu, entre outros resultados, identificar treze (13) fonemas consonantais e cinco (5) vocálicos, inclusive o $\widetilde{\mathrm{tb}_{\mathrm{B}}} /$, que é raro nas línguas no mundo. Também descrevemos o padrão canônico silábico $\mathrm{CV}$, com possibilidades de realizações fonológicas $(\mathrm{C}) \mathrm{V}(\mathrm{C})$, tendo o acento primário como realização fonética e não contrastiva, sempre ocorrendo na última sílaba das palavras.

Outros pontos importantes que descrevemos em nosso trabalho, para a variante Oro Waram Xijein, são os processos fonológicos, como a nasalização, alongamento e redução das vogais; a ocorrência pré-nasalizada das consoantes nasais $/ \mathrm{m} / \mathrm{e} / \mathrm{n} /$, que se realizam como [mb] e [ $\left.{ }^{\mathrm{n}} \mathrm{d}\right]$, ou ainda oralizadas como /b/ e /d/ respectivamente; descrevemos as realizações aspiradas das oclusivas em final de sílaba e de palavra; identificamos que estas consoantes, neste mesmo ambiente, quando não ocorrem aspiradas, se realizam não explodidas.

Uma outra questão importante, e que merece investigação mais aprofundada, é quanto ao processo de laringalização, uma vez que a nossa proposta analisa e descreve esse fenômeno como um processo apenas fonético, o que difere de 
outros trabalhos para outras variantes do Txapakura, que as consideram como fonema.

A análise e descrição da língua Oro Waram Xijein, realizada também por uma falante nativa da língua, foi de suma importância, já que permitiu ao povo, contar com a presença ativa de uma indígena pesquisadora, que tem a possibilidade de se aprofundar nos estudos e entendimento linguísticos sobre sua língua. Isso permitirá a ela e ao povo ainda a possibilidade de discutir com maior propriedade sobre a ortografia e consequentemente sobre o ensino da língua nativa, agora respaldado por um conhecimento que não se tinha anteriormente, pois os estudos sobre esta língua sempre foram feitos pelos não indígenas, tendo os indígenas apenas como informante. Assim, entendemos que $\mathrm{o}$ indígena tem que ser protagonista nesse papel, inclusive proporcionado a ele elaborar e fomentar a produção de materiais didáticos para o ensino de sua língua indígena.

Por fim, sabemos que esse trabalho preliminar foi um passo importante, mesmo que mereça aprofundamentos, pois entendemos que muitos outros estudos devem ser feitos para melhor entendimento e descrição dos fenômenos da língua Oro Waram Xijein, o que pretendemos fazer imediatamente de forma sistemática e contínua para que possamos reunir e produzir vários materiais acessíveis aos professores e alunos indígenas da comunidade, pois são eles que devem ser os principais beneficiados pelos frutos dos trabalhos realizados sobre a língua indígena nativa de sua comunidade.

\section{Referências}

Aikhenvald, Alexandra Y; Dixon, R. M. W. (Org.). 1999a. The Amazon languages, (pp. 107-124). Cambridge: Cambridge University Press.

Apontes, Selmo Azevedo. 2015. Descrição gramatical do oro waram, variante wari' norte (Pakaa Nova, Txapakura): fonologia, morfologia e sintaxe. Tese (Doutorados em Linguística). Belo horizonte: Faculdade de Letras da UFMG.

Barbosa, Plínio A, e Madureira, Sandra. Manual de Fonética Acústica Experimental. 2015. São Paulo: Cortez.

Couto, Fábio Pereira. Conexões entre processos morfofonológicos e acento em Manxineru: a variedade Yine (família Aruák) falada no Brasil. 2016. Tese (Doutorado em Linguística). Brasília, UnB.

Chomsky, Noam, e Halle, Morris. 1968. The sound pattern of english. Evanston, and London: Harper \& Row.

Crystal, D. 2000. Dicionário de Linguística e de Fonética. 2 ed. Rio de Janeiro: Zahar.

Everett, D. L., e Kern, B. 2006. Wari': The Pacaas Novos Language of Western Brazil. Taylor \& Francis e-Library.

Hayes, Bruce. A metrical stress theory the stress rules. 1981. PhD thesis. Cambridge, Mass: MIT. 
Jakobson, Roman, e Halle, Fant. 1956. Fundamentals of Language. Mouton: The Hague.

Jakobson, Roman. 1939 [1972a]. Para a estrutura do fonema. In R. Jakobson. Fonema e fonologia. Trad. e notas de J. Mattoso Câmara Jr. Rio de Janeiro, (pp.15-52). Copenhage: Livr. Acadêmica.

Ladefoged, Peter. 2001. Vowels and Consonants: An introduction to the sounds of languages. Oxford: Blackwell.

Ladefoged, Peter. A Course in Phonetics. 1975. California, Los Angeles: Harcourt Jovanovich, Inc.

Ladefoged, Peter and Everett, Daniel. 1996. The Status of Phonetic Rarities Author(s): Language, v. 72, n. 4 (Dec., 1996), pp. 794-800 Published by: Linguistic Society of America.

Ladefoged, Peter, e Maddieson, Ian. 1996. The Sounds of the World's Languages. Massachusetts-USA: Cambridge.

Maeda, C. T. 2000. Descrição Preliminar do Oro Eo: um caso de sílaba embutida no onset. Dissertação (Mestrado em Linguística). Guajará-Mirim: Campus da UNIR.

Odden, David. 2005. Introducing phonology. Cambridge: Cup.

Pike, Kenneth. 1943. Phonetics a critical account of phonetic theory and a techinique for the pratical description of sounds. Ann Arbor. The University of Michigan Press.

Pike, Kenneth. 1947. Phonemics a Techinique for Reducing to Writing. Ann Arbor. The University or Michigan Press.

Ramirez, H. 2010. Etnônimos e topônimos no Madeira (séculos XVI-XX): um semnúmero de equívocos. Revista Brasileira de Linguística Antropológica 2(2):13-58

Rodrigues, Aryon Dall'Igna. 2002. Linguas Brasileira: Para o conhecimento das línguas indígenas. São Paula: Loyola.

Silveira, Francine. 2007. Vogal epentética no português brasileiro: um estudo acústico em encontros consonantais. Dissertação (Mestrado em Linguística). Florianópolis: Universidade Federal de Santa Catarina.

Sousa, M. de F. L. 2009. Dicionário da língua ‘Wari’: Oro Mon. Português. Dissertação (Mestrado em Ciências da Linguagem). Guajará-Mirim: UNIR. 